\title{
IMPACT OF COGNITIVE DISSONANCE ON CONSUMER BEHAVIOR
}

\author{
Vipin Kumar $^{1}$ and Dr. Rajeev Sharma ${ }^{2}$
}

\begin{abstract}
In Present Marketing Scenario, the Study of Consumer Behavior has become necessary. Without consumers no business organization can drive. All the activities of the business concerns end with consumers and consumer satisfaction. Customer behavior study is based on consumer buying behavior, with the customer playing the three separate roles of user, payer and buyer. Consumer buying behavior has become an undivided part of strategic market planning. The theory of "cognitive dissonance" is also a great importance in consumer behavior and marketers have lots of interest in analyzing the post purchase behavior of consumers experienced by them. This paper has explored the factors that create cognitive dissonance in consumer buying decision making particularly among the consumer goods purchaser in the city area. This article explores the implications of cognitive dissonance on varied aspects of consumer buying behavior.

Keywords: - Consumer Buying Behavior, Marketing, consumer Cognitive dissonance.
\end{abstract}

\section{INTRODUCTION}

Consumer behavior has been always a great interest of marketers. The knowledge of consumer behavior helps the marketer to understand how consumers think, feel and select from alternatives like products, brands and how the consumers are influenced by their environment, the reference groups, and family, cultural, social, personal and psychological factors, salespersons and so on. Cognitive dissonance is one of the most heavily studied phenomena in the history of psychology. The term cognitive dissonance describes a psychological state in which an individual's cognitions-beliefs, attitudes, and behaviors-are at odds (Festinger, 1957). According to cognitive dissonance theory dissonance or want of harmony or inconsistency occurs when an individual holds conflicting thoughts about a belief or an attitude object. When cognitive dissonance occurs after a purchase it is called post purchase dissonance. Because purchase decision often requires some amount of compromise, post purchase dissonance is quite normal. Consumers can rationalize the decision as being wise, seek out advertisements to support their choice or look to known satisfied owners for reassurance (Schiffman \& Kanuk, 2008).

This study will help to identify the influences of cognitive dissonance on consumers in purchasing goods \& services and how marketers can overcome it.

\section{OBJECTIVE OF THE STUDY}

The objective of the study of the above topic is that to identify the factors that create cognitive dissonance in consumer buying decision making particularly among the consumer goods

\footnotetext{
${ }^{1}$ Research Scholar, Institute of Business M anagement, Mangalayatan University, Aligarh

${ }^{2}$ Associate Professor, Institute of Business M anagement, Mangalayatan University, Aligarh
} 
purchaser in the city area. Some of these are family status, religious value, customs, belief etc. the study also reveals the problems and identified probable solutions to overcome these problems.

\section{HYPOTHESIS OF THE STUDY}

1. What factors influence consumer purchases?

2. The marketing concept stresses that a firm should create a Marketing Mix that satisfies customers, therefore need to analyze the what, where, when and how consumers buy.

3. Why consumers make the purchases that they make?

4. Marketers can better predict how consumers will respond to marketing strategies.

5. Analyze the different factors that create cognitive dissonance among the consumers.

\section{CONCEPTUAL DEFINITIONS}

\section{Consumer:-}

A consumer is a person or organization, that uses economic services or commodities.

\section{Consumer Behavior:-}

"The behavior that consumers display in searching for, purchasing, using, evaluating and disposing of products and services that they expect will satisfy their needs." - Schiffman and Kanuk (www.wikipedia.org).

\section{Consumer buying Behavior:-}

Buying Behavior is the decision processes and acts of people involved in buying and using products. (www.wikipedia.org).

\section{Cognitive dissonance:-}

Cognitive dissonance is the mental stress or discomfort experienced by an individual who holds two or more contradictory beliefs, ideas, or values at the same time.

\section{Consumer Behavior}

Consumer Behavior is the study of individuals, groups, or organizations and the processes they use to select, secure, use, and dispose of products, services, experiences, or ideas to satisfy needs and the impacts that these processes have on the consumer and society. It blends elements from psychology, sociology, social anthropology, marketing and economics. It attempts to understand the decision-making processes of buyers, both individually and in groups such as how emotions affect buying behavior. It studies characteristics of individual consumers such as demographics and behavioral variables in an attempt to understand people's wants. It also tries to assess influences on the consumer from groups such as family, friends, sports, reference groups, and society in general.

\section{$5.1 \quad$ Types of consumer behavior}

\begin{tabular}{|l|l|l|}
\hline $\begin{array}{l}\text { Level of Significances } \\
\text { Between Brands }\end{array}$ & High Involvement & Low Involvement \\
\hline Significant & Complex Buying Behavior & $\begin{array}{l}\text { Variety-seeking Buying } \\
\text { Behavior }\end{array}$ \\
\hline Few & $\begin{array}{l}\text { Dissonance-reducing Buying } \\
\text { Behavior }\end{array}$ & Habitual Buying Behavior \\
\hline
\end{tabular}




\subsubsection{Complex Buying Behavior:}

Consumers go through complex buying behavior when they are highly involved in a purchase and aware of significant differences among brands. Consumers are highly involved when the product is expensive, bought infrequently, risky and highly self-expressive. Typically the consumer does not know much about the product category and has much to learn.

Example. A person buying a personal computer may not know what attribute to look for. Many of the product features like "16K.memory" "disc storage", "screen resolution" carry no meaning to him or her.

The marketer of a high-involvement product must understand the information-gathering and evaluation behavior of high-involvement consumers.

\subsubsection{Dissonance-reducing Buying Behavior}

Sometimes the consumer is highly, involved in a purchase but sees little difference in the brands. The high involvement is again based on the fact that the purchase is expensive, infrequent, and risky. In this case, the buyer will shop around to learn what is, available but will buy fairly quickly because brand differences are not pronounced. The buyer may respond primarily to a good price or to purchase convenience.

After the purchase, the consumer might experience dissonance that stems from noticing certain disquieting features of the product or hearing favorable things about other brands. The consumer will be alert to information that might justify his or her decision. The consumer will first act, then acquire new beliefs and end up with a set of attitudes.

\subsubsection{Habitual Buying Behavior:}

Many products are bought under conditions of low consumer involvement and the absence of significant brand differences. Consider the purchase of salt. Consumers have little involvement in this product category. They go to the store and reach for the brand. If they keep reaching for the same brand, it is out of habit, not strong brand loyalty.

Marketers of low-involvement products with few brand differences find it effective to use price and sales promotions to stimulate product trial, since buyers are not highly committed to any brand. In advertising a low-involvement product, a number of things should be observed. The ad copy should stress only a few key points Visual symbols and Imagery are important because they can easily be remembered and associated with the brand.

\subsubsection{Variety-Seeking Buying Behavior:}

Some buying situations are characterized by low consumer involvement but significant brand differences. Here consumers are often observed to do a lot of brand' switching.

An example occurs in purchasing cookies. The consumer has some beliefs, chooses a brand of cookies without much evaluation, and evaluates it during consumption. But next time, the consumer may reach for another brand out of boredom or a wish for a different taste. Brand switching occurs for the sake of variety rather than dissatisfaction.

\subsection{Factors of consumer behavior}

The various factors that influence the consumer behavior are as follows: 


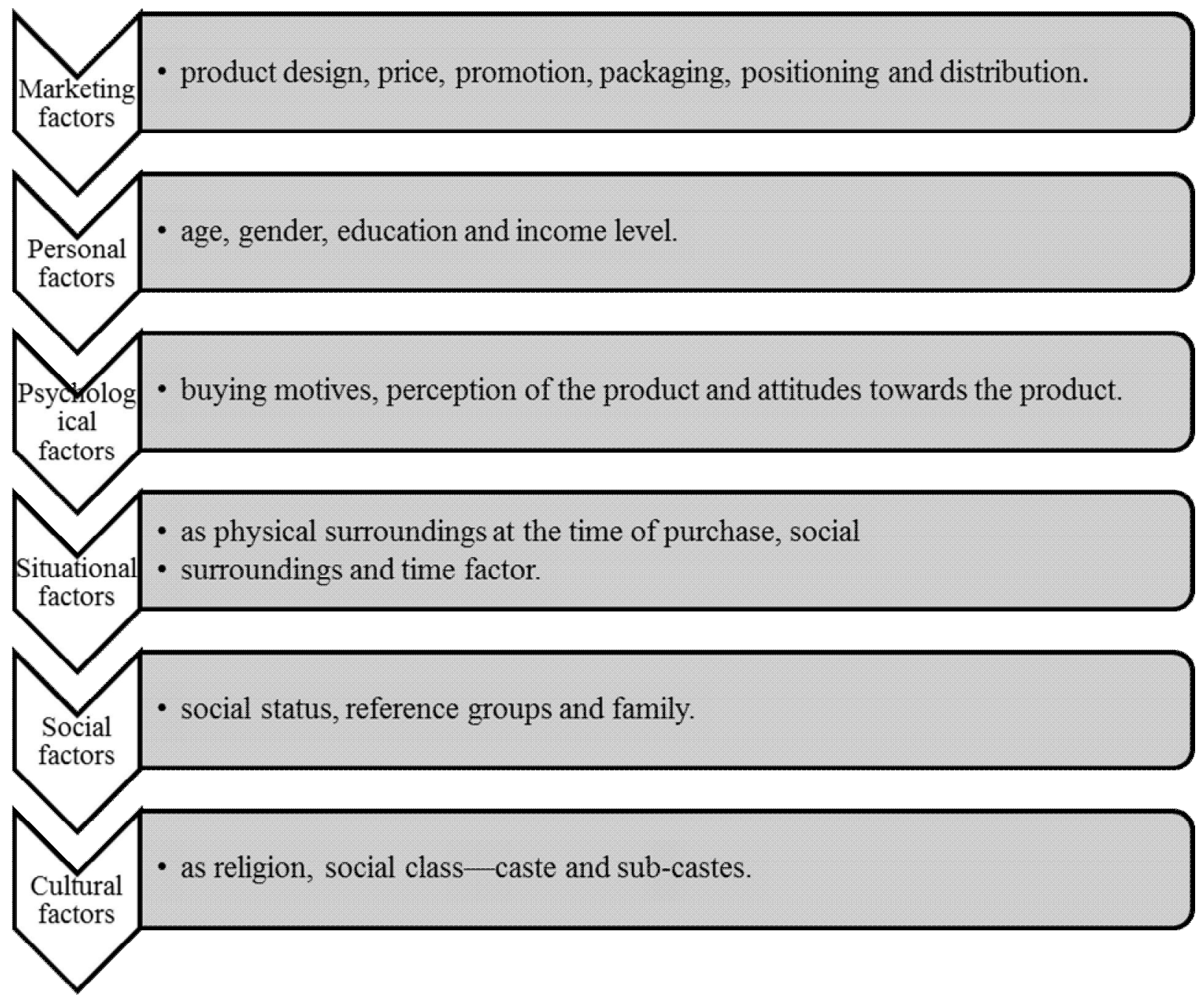

\subsection{Consumer buying process}

Six Stages to the Consumer Buying Decision Process (For complex decisions). Actual purchasing is only one stage of the process. Not all decision processes lead to a purchase. All consumer decisions do not always include all 6 stages, determined by the degree of complexity...discussed next.

The 6 stages are:

1) Problem Recognition (awareness of need)--difference between the desired state and the actual condition. Deficit in assortment of products. Hunger-Food. Hunger stimulates your need to eat. Can be stimulated by the marketer through product information--did not know you were deficient? I.E., see a commercial for a new pair of shoes, stimulates your recognition that you need a new pair of shoes.

\section{2) Information search--}

- Internal search, memory. 
- $\quad$ External search if you need more information. Friends and relatives (word of mouth). Marketer dominated sources; comparison shopping; public sources etc. A successful information search leaves a buyer with possible alternatives, the evoked set. Hungry, want to go out and eat, evoked set is
- $\quad$ Chinese food
- $\quad$ Indian food
- $\quad$ Burger king etc.

3) Evaluation of Alternatives--need to establish criteria for evaluation, features the buyer wants or does not want. Rank/weight alternatives or resume search. May decide that you want to eat something spicy, In Indian gets highest rank etc. If not satisfied with your choice then returns to the search phase. Can you think of another restaurant? Look in the yellow pages etc. Information from different sources may be treated differently. Marketers try to influence by "framing" alternatives.

4) Purchase decision--Choose buying alternative, includes product, package, store, method of purchase etc.

5) Purchase--May differ from decision, time lapse between $4 \& 5$, product availability.

6) Post-Purchase Evaluation--outcome: Satisfaction or Dissatisfaction. Cognitive Dissonance, have you made the right decision. This can be reduced by warranties, after sales communication etc.

\section{COGNITIVE DISSONANCE}

Cognitive dissonance is a psychological phenomenon which refers to the discomfort felt at a discrepancy between what you already know or believe, and new information or interpretation. It therefore occurs when there is a need to accommodate new ideas, and it may be necessary for it to develop so that we become "open" to them makes the generation of appropriate dissonance into a major feature of teaching: he shows how to drive this kind of intellectual wedge between learners' current beliefs and "reality".

Cognitive dissonance was first investigated by Festinger (1957) and associates, arising out of a participant observation study of a cult which believed that the earth was going to be destroyed by a flood, and what happened to its members - particularly the really committed ones who had given up their homes and jobs to work for the cult — when the flood did not happen.

A social psychologist describes cognitive dissonance as a psychological phenomenon that occurs when there exists a discrepancy between what a person believes in and the outcome which questions a person ${ }^{\text {ec }}$ belief (Festinger, 1957). Festinger described cognitive dissonance as a state which comes into existence when a person gets confused between two cognitions (thoughts), which cannot exist together and hence create tension for him. As the person believes both the thoughts to be true, it invokes mental tension in his mind. The resulting dissonance motivates the individual to bring harmony to inconsistent elements and thereby reduce psychological tension.

\subsection{Dissonance in Consumer Behavior}


In dynamic business environment, marketers have always been trying to not only acquire new customer base but also retain the existing one by providing value, satisfying customers' exchange expectations. It has been found that customer retention is highly associated with customer satisfaction and customer satisfaction not only retains the customer with the company but also affects revenue, earning per share and stock price (Williams and Naumann, 2011).

Since consumer behavior and its extensive study has been a backbone of the marketing strategy of every firm, a detailed and comprehensive study of all its aspects become imperative for the success of an organization. And, hence, the concept of cognitive dissonance and its effect on the consumer behavior has been a part of various significant research studies as well. One author even termed it one of social psychology's greatest theories (Aronson 1969).Sweeney, Hausknecht and Soutar (2000) noted, ,dissonance includes both cognitive aspects, as the title „,cognitive dissonance ${ }^{\text {e }}$ implies, as well as an emotional dimension, as many definitions, including Festinger's original definition, imply.

The resulting dissonance motivates the individual to bring harmony to inconsistent elements and thereby reduce psychological tension. Dissonance is known to arise mainly in three ways -First, any logical inconsistency can create dissonance. Second, dissonance can be created when a person experiences an inconsistency either between his attitude and his behavior or between two of his behaviors. Third, dissonance can occur when a strongly held expectation is disconfirmed, notes Loudon \& Della Bitta (2002). Further, dissonance occurs once a decision has been made as prior to making a decision an individual had an option of adjusting to any attitude or behavior which he deemed right as per his choice but once a decision is being made, a commitment has been established between the buyer and the consumer, where he cannot further adjust himself and is liable to stick to his decision.

\subsection{Factors Creating Cognitive Dissonance}

People tend to seek consistency in their beliefs and perceptions. The term cognitive dissonance is used to describe the feeling of discomfort that results from holding two conflicting beliefs. When there is a disqualification between beliefs and behaviors, something must change in order to eliminate or reduce the dissonance. Several factors are responsible for creating cognitive dissonance. Some of these are like values, belief, attitudes, customs, political philosophy, religious value, emotional reaction, norms, culture, social status, peer group influence etc.

People living in a particular culture may hold a strong belief that he or she should purchase that product that must be accepted by that particular culture. In purchasing products conflict may arise regarding whether to purchase or not. Will it be accepted by my society? This situation creates cognitive dissonance. Besides people may have different values, belief, customs which might create dissonance in case of purchasing products. A religious value is one of the most important factors which are responsible for generating cognitive dissonance. People of different religion purchase items based on their religious belief. Some items are strongly prohibited by some religion and when people purchasing those, it creates dissonance. In addition to this political value, emotional reactions, social status also affect purchase decision and thus creating cognitive dissonance (Bhasin, 2010).

\subsection{How to Reduce Cognitive Dissonance}

There are three key strategies to reduce or minimize cognitive dissonance: 
- $\quad$ Focus on more supportive beliefs that overcharge the dissonant belief or behavior.

- $\quad$ Reduce the importance of the conflicting belief.

- Change the conflicting belief so that it is consistent with other beliefs or behaviors.

\subsection{Foundations of Dissonance Theory}

The theory of cognitive dissonance is gorgeously simple: it states that inconsistency between two cognitions creates an aversive state akin to hunger or thirst that gives rise to a motivation to reduce the inconsistency. According to Leon Festinger ( 1957), cognitions are elements of knowledge that people have about their behavior, their attitudes, and their environment. As such, a set of cognitions can be unrelated, consonant, or dissonant with each other. Two cognitions are said to be dissonant when one follows from the obverse of the other. The resultant motivation to reduce dissonance is directly proportional to the magnitude and importance of the discrepant cognitions, and inversely proportional to the magnitude and importance of the consistent cognitions. This tension is typically reduced by changing one of the cognitions, or adding new cognitions until mental 'consonance' is achieved. Festinger's original formulation proved to be one of the most robust, influential, and controversial theories in the history of social psychology. Although a number of challenges and revisions have been suggested, the basic behavioral observation remains uncontested and continues to stimulate fresh research.

Application of this theory has yielded many surprising and nonintuitive predictions. For example, conventional wisdom suggests that behavior follows from attitudes; dissonance theory, however, identifies conditions under which just the opposite occurs. An early and often replicated experiment illustrates the power and counter intuitiveness of the theory. In what is now known as the induced compliance effect, Festinger and Carlsmith (1959) asked individuals to perform 30 minutes of a mind- numbingly tedious activity, and then to persuade a waiting participant that the activity was in fact quite interesting. This situation created cognitive dissonance in most individuals - they believed that the task was boring, yet inexplicably found themselves arguing quite the opposite.

The theory of cognitive dissonance (Festinger 1957) states that inconsistency between beliefs or behaviors creates an aversive motivational state akin to hunger or thirst. This tension is typically reduced by changing one of the dissonant elements, or adding new ones, until mental consonance is achieved. There have been three major revisions relevant to modern interpretation of dissonance phenomena. Aronson's self consistency model ( 1968) proposed that dissonance resulted from behaviors that were discrepant with one's conception of oneself as a decent and sensible person. Steele's self-affirmation theory ( 1988) proposed that dissonance emerged from threats to the overarching self- system, and that dissonance reduction relied on re-establishing the integrity of the global self-concept. Cooper and Fazio's 'New Look' model ( 1984) proposed that dissonance resulted from creating unwanted aversive consequences and did not require cognitive inconsistency. A recent synthesis discussed by Cooper (1999) and Stone ( 1999) suggests that dissonance is caused by a discrepancy between the outcome of a behavioral act and the standard to which it is compared. According to this self-standards model, contextual variables determine the comparison standard, and it is this standard that determines which dissonance process is most likely to be operative.

\section{CONCLUSION}


This study also has suggested some strategy which service organization might reduce cognitive dissonance. Today with the rapid growth of service industry marketers of different service organizations are facing major challenges to meet up customers expectations. Therefore it is important for the service organization to dissonance related to purchasing and thus sustain in the competition in the local as well as in the global markets. After analyzing the outcome of the survey analysis the study has recommended some of the strategies which might be effective in reducing cognitive dissonance. These are:

1. Focus on more encouraging beliefs that offset the dissonant belief or behavior.

2. Reduce the importance of the contradictory belief.

3. Change the conflicting belief so that it is consistent with other beliefs or behaviors.

4. Looking for credible source which the target consumers trust. At the same time word-of- mouth communications need to be increased.

5. Emphasize on selecting a likeable source.

6. $\quad$ Finding out the sources which match customer's previous belief.

7. Unexpected source sometimes may have more impact on consumer's attitudes.

\section{REFERENCES}

[1]. Duesenberry, J.S. Income saving and Theory of consumer Behavior, Cambridge Harvard University Press, 1949

[2]. Engel, F. James, Consumer Behavior, New David, T. Kollat and York: Holt Rinehart \& Winston Roger, D. Blackwell Inc,1968

[3]. Howard, John A. Consumer Behaviour-Application of Theory, New york: Mc Graw Hill Book Co., 1977

[4]. Mahajan, B.M. Consumer Behaviour in India, New Delhi, Concept Publishing Co., 1980

[5]. Festinger Leon (1957), a theory of Cognitive Dissonance, Stanford University Press,Stanford, CA

[6]. Koller Monika and Salzberger Thomas (2007), "Cognitive Dissonance as a Relevant Construct throughout the Decision-Making and Consumption Process:An Empirical Investigation Related to a Package Tour", Journal of Customer Behavior, Vol. 6, No. 3

[7]. Cognitivedissonance.(2012).InWikipedia.RetrievedMarch14fromen.wikipedia.org/wiki/Cognitive dissonance.

[8]. Smith J Brock and Bristor J M (2006), "Uncertainty Orientation: Explaining Differences in Purchase Involvement and External Search", Psychology and Marketing, Vol. 11,No. 6 